\title{
A rare case of a functioning retroperitoneal paraganglioma in a patient with recurrent Phaeochromocytoma/Paraganglioma(PPGL)
}

D Hope ${ }^{1}$, R Kehinde 1 , Q Barnor

${ }^{1}$ Department of Diabetes \& Endocrinology, Watford General Hospital, West Hertfordshire Hospitals NHS Trust

\section{INTRODUCTION TO CASE}

Paragangliomas are rare neuroendrocrine tumours arising from extra-adrenal paraganglia of the autonomic nervous system. Catecholamine excess is associated with higher cardiovascular mortality. Paragangliomas may arise from sympathetic paravertebral ganglia of thorax, abdomen, and pelvis or the parasympathetic ganglia located along the glossopharyngeal and vagal nerves in the neck and at the base of the skull. (1)

Case detection is important due to a high proportion of familial disease. Phaeochromocytomas/Paragangliomas (PPGLs) have malignant potential (prevalence varies between 10 and 17\%). Mutations in the gene encoding SDH subunit B (SDHB) can lead to metastatic disease in $40 \%$ or more of the patients. (1)

Management is divided in to peri-operative and operative. Alpha-adrenergic blockade pre-operatively is essential to prevent perioperative cardiovascular complications. The surgical approach to resection of PPGLs depends on size and site of the tumour. (1)

We present the case of a 56-year old Polish male referred to our outpatient clinic following an incidental finding of a retroperitoneal mass whilst undergoing investigation for a ureteric calculus. He described symptoms of sympathetichyperactivity, including excessive sweating, palpitations and diastolic hypertension (140/100 $\mathrm{mmHg}$ ). He also described a 3 month history of sweating and flushing exacerbated by moving to a recumbent position.

He had undergone bilateral thoracotomy and laparotomy on separate occasions in Poland many years ago to remove paragangliomas in the head, neck and abdomen, in 1996 and 2009, respectively. He also reported a strong family history of paraganglioma/phaeochromocytoma type 1 (PPGL-1) in his father, paternal grandfather, brother, sister and aunt.

Polish medical reports document a mutation in the SDHD gen consistent with high genetic penetrance, however there had been a loss to follow up from routine surveillance. Current medications included doxazosin $4 \mathrm{mg}$ daily.

\section{INVESTIGATIONS}

24-hour urinary catecholamines revealed Normetadrenaline $14304 \mathrm{nmol} / 24 \mathrm{hr}(0-3300)$, Metadrenaline $132 \mathrm{nmol} / 24 \mathrm{hr}(0-1200)$, 3Methoxytyramine $979 \mathrm{nmol} / 24 \mathrm{hr}(0-2500)$.

Table 1: 24-hr urine metanephrines.

\begin{tabular}{|l|l|l|l|}
\hline $\begin{array}{l}\text { Urine } \\
\text { catecholamines }\end{array}$ & $\begin{array}{l}\text { Normetadrenaline } \\
\text { (nmol/24hr) }\end{array}$ & $\begin{array}{l}\text { Metadrenaline } \\
\text { (nmol/24hr) }\end{array}$ & $\begin{array}{l}\text { 3-Methoxy- } \\
\text { tyramine } \\
\text { (nmol/24hr) }\end{array}$ \\
\hline Level & $14304(0-3300)$ & $132(0-1200)$ & $979(0-2500)$ \\
\hline
\end{tabular}

Table 2: Blood tests:-

\begin{tabular}{|c|c|c|}
\hline Test & Result & \multirow{9}{*}{$\begin{array}{l}\text { Due to significant } \\
\text { biochemical activity of a } \\
\text { recurrent PPGL, he was } \\
\text { commenced on alpha- } \\
\text { blockade with } \\
\text { Phenoxybenzamine 10mg } \\
3 x / \text { day prior to } \\
\text { propranolol } 40 \mathrm{mg} \text { twice } \\
\text { daily. } \\
\text { Further imaging was } \\
\text { requested in the first } \\
\text { instance a triple phase CT } \\
\text { scan of the abdomen and } \\
\text { pelvis. }\end{array}$} \\
\hline TSH & $\begin{array}{l}0.47(0.3- \\
4.2 \mathrm{mU} / \mathrm{I})\end{array}$ & \\
\hline T4 & 12.9 & \\
\hline Cortisol & 137 & \\
\hline PTH & $\begin{array}{l}6.8(1.1- \\
6.8 \mathrm{pmol} / \mathrm{l})\end{array}$ & \\
\hline Somatostatin & $26(0-150 \mathrm{pmol} / \mathrm{l})$ & \\
\hline Glucagon & $10(0-50 \mathrm{pmol} / \mathrm{l})$ & \\
\hline Gastrin & $10(0-40 \mathrm{pmol} / \mathrm{l})$ & \\
\hline Chromogranin A & 39 (0-60pmol/l) & \\
\hline
\end{tabular}

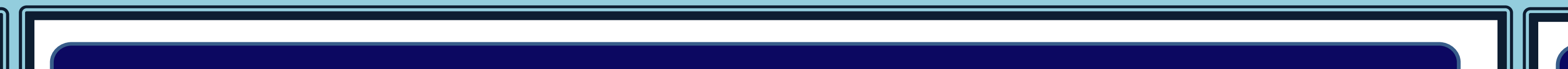

\section{PROGRESS}

\section{Patient progress:-}

The patient subsequently recovered his past medical documents including a significant family history in several family members which confirmed a previous diagnosis of PPGL with a mutation in the SDHD gene.

He was subsequently referred for surgery at our local tertiary centre including ENT assessment for bilateral neck tumours. He is currently awaiting surgery for the recurrent tumours. He was also referred to urology for left ureteric stenting.

Alpha-blockade pre-operative medication was optimised to $10 \mathrm{mg}$ am, $20 \mathrm{mg} 3 \mathrm{pm}$ and $10 \mathrm{mg} 9 \mathrm{pm}$.

\section{Recurrent PPGLS:}

For SDHx -related PPGLs, overall sensitivity of 123 MIBG is less than $50 \%$ (1). Similar results have been reported for the detection of skull base, neck, thoracic, bladder, or recurrent paragangliomas(1).

${ }^{68} \mathrm{Ga}$-DOTATATE PET/CT has demonstrated superiority in lesion detection (sensitivity $93 \%$, specificity $96 \%$ ) compared to Octreoscan, MIBG scintigraphy and MRI (2).

Guidelines recommend lifelong annual biochemical testing to assess for recurrent or metastatic disease (1).

\section{IMAGING}

Figure 2. NM Ga68 Dotatate PET/CT abdomen



Figure 5.NM uptake scan whole body
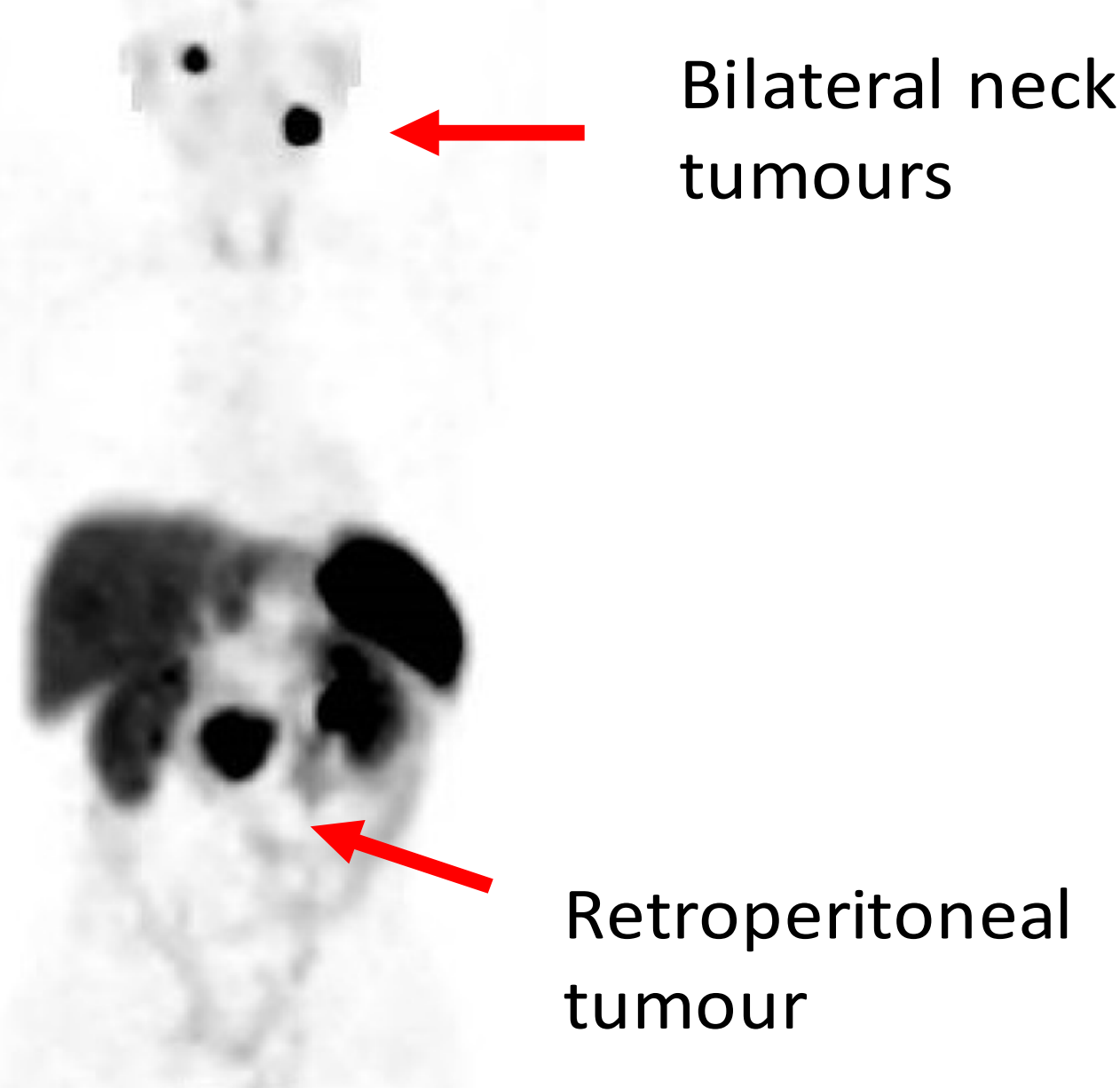

Figure 1 CT abdomen (top left): Showing a well defined retroperitonea aortocaval mass $4.4 \mathrm{~cm} \times 4.5 \mathrm{~cm}$ at the level of $L 2$, displacing the aorta and IVC laterally. A left partially obstructing ureteric calculus was also seen. Figure 2 NM Ga68 Dotatate PET CT abdomen (top right): There is a intensely tracer avid para-aortic mass lying at the level of the kidneys measuring approximately $44 \mathrm{~mm}$ in the axial dimension.

Figure 3 NM Ga68 Dotatate PET CTneck (middle left): There is an intensely avid lesion adjacent to the left common carotid artery at the angle of the left mandible measuring approximately $14 \mathrm{~mm}$. Figure 4 NM Ga68 Dotatate PET CT neck (lower left): Intensely trace avid lesion anterior to the right side of the $\mathrm{C} 1$ arch (glomus vagale). approximately $12 \mathrm{~mm}$. No bony or skull base erosion. Figure 5 NM uptake scan whole body (middle right): Showing abdomina and neck lesions. The distribution of tracer elsewhere is physiological.

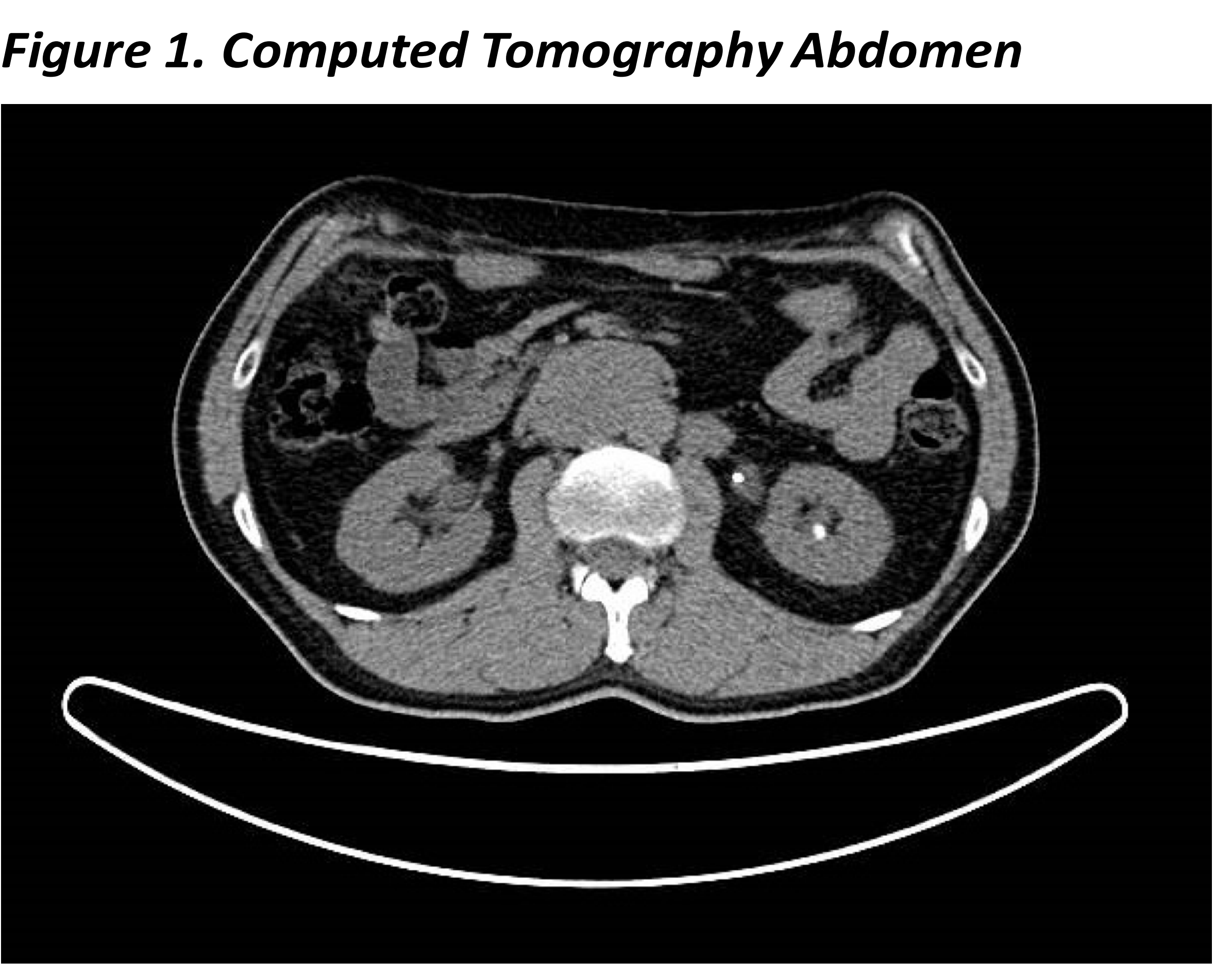

Figure 3. NM Ga68 Dotatate PET/CT neck

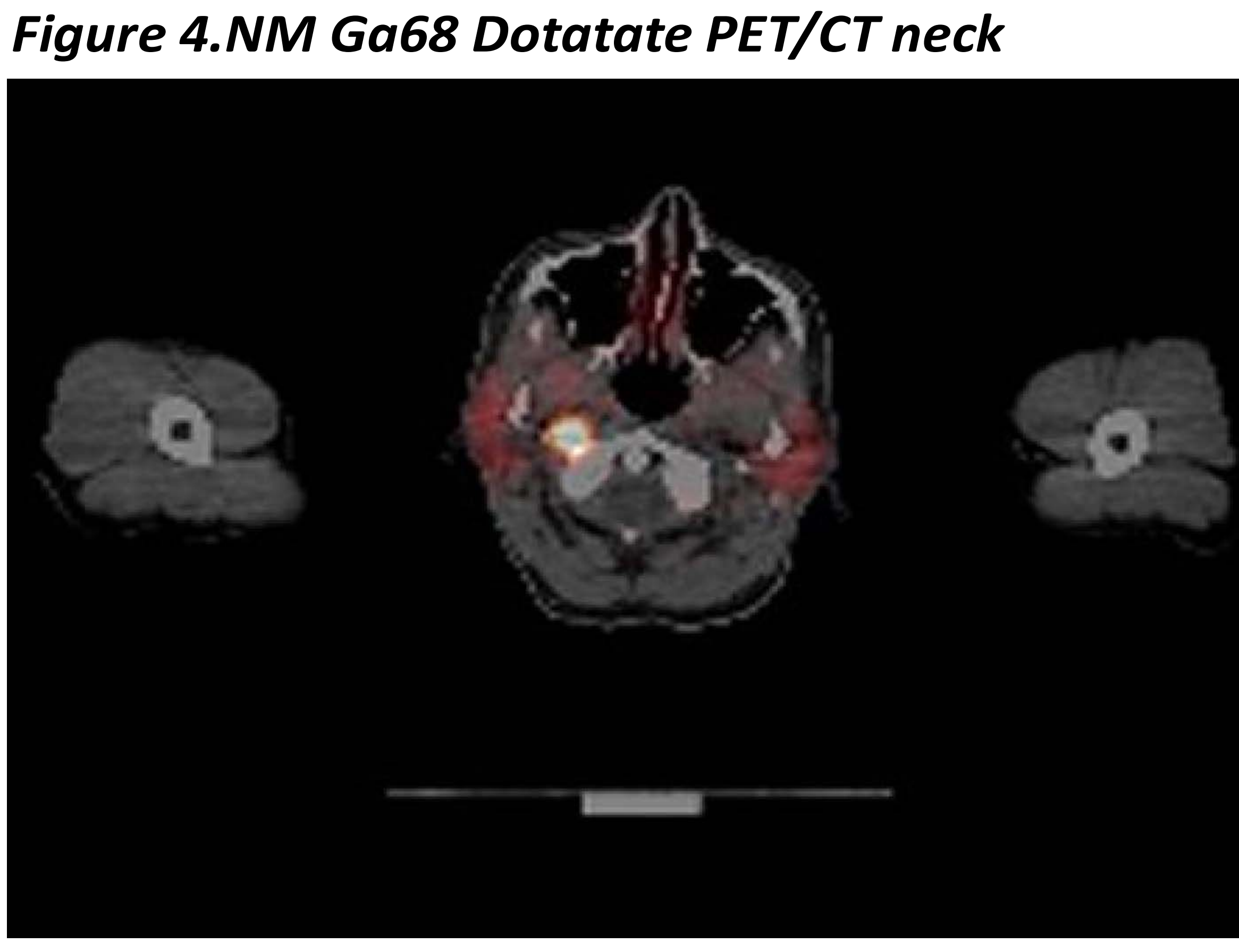

\section{CONCLUSION}

A high index of suspicion for recurrence/metastasis should be maintained in certain genetic subtypes of PPGL, for example SDHB-related PPGL. Adequate surveillance should be instituted under guidance from centres with expertise in managing these tumours.

Imaging should be tailored to suspected tumour location and disease burden. With improved spatial resolution of CT/PET combined with nuclear medicine tracers for example 68-Ga Dotatate, diagnostic accuracy is high.

Biochemical evaluation as part of routine follow-up in patients with known PPGL is essential to detect recurrent disease, for example in this case retroperitoneal and neck paragangliomas.

Surgical resection is established as the only curative option. Early excision is recommended due to the risk of malignant transformation. Other management options include radiation therapy, chemotherapy, ablation therapy, embolization, or targeted therapy such as tyrosine kinase inhibitors.

References. 1. Pheochromocytoma and Paraganglioma: An Endocrine Society Clinical Practice Guideline. JCEM 2014.

2. Geijer H and Breimer L.H. 2013. Somatostatin receptor PET/CT in neuroendocrine tumours: update on systematic review and metaanalysis. European Jounral of nuclear medicine and molecular imaging. 